Check for updates

Cite this: RSC Adv., 2017, 7, 30345

\title{
Double conjugated nanogels for selective intracellular drug delivery $\dagger$
}

\author{
Emanuele Mauri, ${ }^{a}$ Pietro Veglianese, ${ }^{\text {b }}$ Simonetta Papa, ${ }^{\mathrm{b}}$ Alessandro Mariani, ${ }^{\mathrm{c}}$ \\ Massimiliano De Paola, ${ }^{c}$ Riccardo Rigamonti, ${ }^{a}$ Giulia M. F. Chincarini, ${ }^{a}$ Irma Vismara, ${ }^{b}$ \\ Stefano Rimondo, ${ }^{a}$ Alessandro Sacchetti ${ }^{\star a}$ and Filippo Rossi $\left(\mathbb{D} \ddagger^{\star a}\right.$
}

\begin{abstract}
One of the most important drawbacks of nanomedicine is related to the unwanted rapid diffusion of drugs loaded within nanocarriers towards the external biological environment, according to the high clearance of body fluids. Therefore, colloids can carry only a small amount of their initial content in the target district, limiting their pharmacological activity and then the therapy. To overcome this limitation, we synthesized double conjugated nanogels: the first click strategy (1,3 Huisgen cycloaddition) guarantees the traceability of nanogels while the second one (disulfide bond) links drug molecules to polymeric chains. In this study, we proposed the above-mentioned double strategy and we validated the synthesized colloids and the selective release kinetics in microglia cells, dramatically involved in several diseases of the central nervous system. Cleavable linked drugs prove to be a promising tool for the selective administration of pharmacological compounds in microglia cells and potentially in many others counteracting some relevant events.
\end{abstract}

Received 24th April 2017

Accepted 7th June 2017

DOI: $10.1039 / \mathrm{c} 7 \mathrm{ra0} 4584 \mathrm{k}$

rsc.li/rsc-advances years. ${ }^{13-15}$ These state-of-the-art systems are able to transport the loaded compounds specifically to the target cells and release their payload once there, following controlled or sustained kinetics. ${ }^{\mathbf{1 6 - 1 8}}$ This approach, firstly used in cancer treatment, has now been extended to several other districts and diseases. ${ }^{19-22}$ Among them, in the last years a lot of attention was dedicated to nanosystems able to selectively deliver drugs in the damaged central nervous system using the high phagocytic activity of microglia. ${ }^{23,24}$

Along these lines, Papa and coworkers developed, for

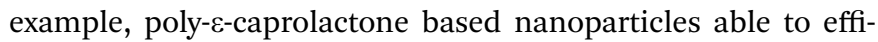
ciently modulate resident microglial cells reducing their proinflammatory response, maintaining a pro-regenerative milieu and ameliorating the behavioral outcome in mice up to 63 days post spinal cord injury. ${ }^{25}$ In addition, this novel pharmacological delivery by nanocarriers presents important improvements, namely a selective drug delivery and a maximized pharmacological activity (anti-inflammatory effect) compared to other administration routes such as direct parenchymal or intraperitoneal injection.

Cerqueira and coworkers proved that the intracellular internalization of high concentration of methylprednisoloneloaded CMCht/PAMAM dendrimer nanoparticles modulates the metabolic activity of microglia cells in vitro and in vivo. ${ }^{26}$ These strategies promised to be very efficient, but the main limitation resides in the fact that the drug loaded could be released during the transition to the target and the quantity of drug that can be delivered in the site is generally very low. ${ }^{27-29}$

To overcome these drawbacks, a promising strategy is represented by the use of cleavable bonds between polymer and 
drug molecules. ${ }^{30-32}$ Following this strategy, drug release is not driven by Fickian diffusion but it is delayed by the stability of the bond between drugs and polymer: the higher the stability, the slower the release rates. ${ }^{3,34}$ The most common strategy in order to functionalize polymers with drugs is represented by polymer post-polymerization modification also known as click strategies. ${ }^{30,35,36}$ Indeed, the presence of functional groups in polymerization reaction may completely prevent polymerization, modify polymer properties (molecular weight, polydispersity, crystallinity, etc.) or lead to side effects.

In this work we decided to functionalize nanogels (NGs) composed by polyethylene glycol (PEG) and polyethyleneimine (PEI) interconnections with a commonly used mimetic drug rhodamine $\mathrm{B}(\mathrm{RhB})^{37,38}$ (click 1) using disulfide bond that can be disrupted by glutathione present within cell cytosol. ${ }^{39,40}$ In order to be traceable, the nanogels were also functionalized with Cy5 dye (click 2) using Huisgen 1,3-cycloaddition. The synthesis, characterization and size of nanocarriers were evaluated together with their ability to release mimetic drug within microglia cells. This study represents a good proof of concept of the possibility to optimize dye and drug-conjunctions to polymers to guarantee traceability on one side and improve drug delivery performances on the other.

\section{Experimental}

\section{Materials}

Polyethyleneimine linear (PEI, $M_{\mathrm{W}}=2500 \mathrm{Da}$ ) was purchased from Polysciences Inc. (Warrington, USA), whereas polyethylene glycol 8000 (PEG, $\left.M_{\mathrm{W}}=8000 \mathrm{Da}\right)$, rhodamine, Cy5 dye and all other used chemicals were purchased from Sigma-Aldrich (Sigma Aldrich Chemie GmbH, Deisenhofen, Germany). The materials were used as received. Solvents were of analytical grade. Rhodamine derivatives were stored at $4{ }^{\circ} \mathrm{C}$ in dark. Synthetized products with Cy5 moiety were stored at $-20{ }^{\circ} \mathrm{C}$.

\section{Characterization and analyses}

The NMR experiments were carried out on a Bruker AC (400 $\mathrm{MHz}$ ) spectrometer using chloroform $\left(\mathrm{CDCl}_{3}\right)$ or deuterium oxide $\left(\mathrm{D}_{2} \mathrm{O}\right)$ as solvent, and chemical shifts were reported as $\delta$ values in parts per million with respect to TMS as internal standard. Final sizes and $\zeta$-potentials of nanogels were determined by dynamic light scattering (DLS) analysis using a Zetasizer Nano ZS from Malvern Instruments and the reported data are an average value of three measurements of the same sample, dissolved in distilled water. Atomic force microscopy (AFM) analysis was performed for the characterization of nanogel latexes using a NT-MDT Solver Pro instrument operating in noncontact mode with silicon tips. Samples were prepared by dropping latexes onto silicon substrate and drying. AFM images on $1 \times 1 \mu^{2}$ areas were recorded for the preliminary morphologic evaluation; $500 \times 500 \mathrm{~nm}^{2}$ image were then cropped and height line profile performed for single gel. Surface morphology was evaluated by flattening of the images (first order) using NT-MDT software.

\section{Nanogel synthesis}

Synthesis of amine modified rhodamine 1. The functionalization of rhodamine $\mathrm{B}$ base with amine moiety was performed referring to the method discussed by Alam and coworkers. ${ }^{\mathbf{4 1}}$ Briefly, rhodamine $(1.2 \mathrm{~g}, 2.5 \mathrm{mmol})$ was dissolved in ethanol (30 ml) and ethylenediamine $(220 \mu \mathrm{l}, 3.25 \mathrm{mmol})$ was added dropwise at room temperature. The mixture was kept stirring, heating to reflux for $72 \mathrm{~h}$, until colour change from violet to orange occurred. The solvent was evaporated under reduce pressure. Excess of diethyl ether $(40 \mathrm{ml})$ was added and the resulting precipitate was collected by vacuum filtration and dried under vacuum to obtain the product as a powder $(75 \%$ yield). The modified rhodamine was verified by ${ }^{1} \mathrm{H}-\mathrm{NMR}$ analysis. ${ }^{1} \mathrm{H} \mathrm{NMR}\left(400 \mathrm{MHz}, \mathrm{CDCl}_{3}\right): \delta 7.90(\mathrm{~m}, J=5.3 \mathrm{~Hz}, 1 \mathrm{H}), 7.48-$ $7.37(\mathrm{~m}, 2 \mathrm{H}), 7.09(\mathrm{~m}, J=4.6 \mathrm{~Hz}, 1 \mathrm{H}), 6.43(\mathrm{~d}, J=8.7 \mathrm{~Hz}, 2 \mathrm{H})$, $6.38(\mathrm{~d}, 2 \mathrm{H}), 6.32-6.18(\mathrm{dd}, 2 \mathrm{H}), 3.33(\mathrm{q}, J=7.3 \mathrm{~Hz}, 8 \mathrm{H}), 3.18(\mathrm{t}$, $J=6.6 \mathrm{~Hz}, 2 \mathrm{H}), 2.41(\mathrm{t}, J=6.6 \mathrm{~Hz}, 2 \mathrm{H}), 1.16(\mathrm{t}, J=7.0 \mathrm{~Hz}, 12 \mathrm{H})$.

Found: C, 74.08; $\mathrm{H}, 7.83 ; \mathrm{N}, 11.52$. Calc. for $\mathrm{C}_{30} \mathrm{H}_{38} \mathrm{~N}_{4} \mathrm{O}_{2}$ : C, $74.04 ; \mathrm{H}, 7.87$; N, 11.51\%.

Synthesis of 2-propynoxyethyldisulphanylethanol 2. Referring to the procedure of $\mathrm{Li}$ and coworkers, ${ }^{42}$ 2-hydroxyethyl disulfide (10 g, $64 \mathrm{mmol})$ was dissolved in THF $(100 \mathrm{ml})$; the solution was cooled to $0{ }^{\circ} \mathrm{C}$ and then propargyl bromide $80 \%$ in toluene (3.6 g, $32 \mathrm{mmol}$ ) and sodium hydride $(1.15 \mathrm{~g}, 38 \mathrm{mmol})$ were added. The system was stirred for $10 \mathrm{~h}$ at room temperature and, successively, 10 drops of distilled water were added to stop the reaction. The mixture was filtered and the solvent was removed under reduced pressure. The crude product was purified by column chromatography (hexane : ethyl acetate $9: 1 \mathrm{v} / \mathrm{v}$ ) resulting in a pale-yellow oil (60\% yield), which was characterized by NMR analysis. ${ }^{1} \mathrm{H} \mathrm{NMR}\left(400 \mathrm{MHz}, \mathrm{CDCl}_{3}\right): \delta 4.20(\mathrm{~d}, J=$ $2.0 \mathrm{~Hz}, 2 \mathrm{H}), 3.93-3.86(\mathrm{t}, 2 \mathrm{H}), 3.83-3.74(\mathrm{t}, 2 \mathrm{H}), 2.93(\mathrm{t}, J=$ $6.4 \mathrm{~Hz}, 2 \mathrm{H}), 2.89(\mathrm{t}, J=5.9 \mathrm{~Hz}, 2 \mathrm{H}), 2.47(\mathrm{t}, J=2.4 \mathrm{~Hz}, 1 \mathrm{H})$, 2.04 (s, 1H).

Found: C, 43.68; H, 6.30. Calc. for $\mathrm{C}_{7} \mathrm{H}_{12} \mathrm{O}_{2} \mathrm{~S}_{2}$ : C, 43.72; H, 6.29 .

Synthesis of alkyne modified rhodamine-disulfide bridge 3 . Separately, 1,1'-carbonyldiimidazole (CDI, $50 \mathrm{mg}, 0.31 \mathrm{mmol}$ ) was dissolved in $\mathrm{CH}_{2} \mathrm{Cl}_{2}(2 \mathrm{ml})$ and $2(59.5 \mathrm{mg}, 0.31 \mathrm{mmol})$ was dissolved in other $\mathrm{CH}_{2} \mathrm{Cl}_{2}(2 \mathrm{ml})$. The latter was added dropwise to the CDI solution, at $0{ }^{\circ} \mathrm{C}$ and the resulting mixture was stirred for $4 \mathrm{~h}$. Then, functionalized rhodamine 1 (150 $\mathrm{mg}, 0.31 \mathrm{mmol})$ was added and the final system was left stirring for $16 \mathrm{~h}$ at room temperature. The desired product was recovered after extraction using $\mathrm{HCl} 1 \mathrm{M}(3 \times 5 \mathrm{ml})$ : the organic phase was dried over anhydrous sodium sulfate, filtrated and concentrated under vacuum to get a purple solid (85\% yield). ${ }^{1} \mathrm{H}$ NMR $(400 \mathrm{MHz}$, $\left.\mathrm{CDCl}_{3}\right): \delta 7.95-7.74(\mathrm{~m}, 1 \mathrm{H}), 7.51-7.30(\mathrm{~m}, 2 \mathrm{H}), 6.99(\mathrm{~m}, J=5.8$, $2.7 \mathrm{~Hz}, 1 \mathrm{H}), 4.19-4.06(\mathrm{~d}, 2 \mathrm{H}), 3.83(\mathrm{t}, J=5.8 \mathrm{~Hz}, 2 \mathrm{H}), 3.77-3.68$ $(\mathrm{t}, 2 \mathrm{H}), 3.31(\mathrm{q}, J=7.3 \mathrm{~Hz}, 8 \mathrm{H}), 3.25(\mathrm{t}, J=6.6 \mathrm{~Hz}, 2 \mathrm{H}), 2.90(\mathrm{t}, J=$ $5.9 \mathrm{~Hz}, 2 \mathrm{H}), 2.39(\mathrm{t}, J=2.2 \mathrm{~Hz}, 1 \mathrm{H}), 1.16(\mathrm{t}, J=7.6,6.9 \mathrm{~Hz}, 12 \mathrm{H})$.

Found: C, 64.77; H, 6.89; N, 7.92. Calc. for $\mathrm{C}_{38} \mathrm{H}_{48} \mathrm{~N}_{4} \mathrm{O}_{5} \mathrm{~S}_{2}$ : C, 64.74; H, 6.86; N, 7.95.

Synthesis of diepoxy PEG 4. Diepoxy-terminated PEG was synthetized referring to the procedure discussed by Teodorescu and coworkers. ${ }^{43}$ Briefly, PEG (2 g, $0.25 \mathrm{mmol}$ ) and epichlorohydrin 
(587 $\mu \mathrm{l}, 7.50 \mathrm{mmol})$ were dissolved in toluene $(12 \mathrm{ml})$ and then, $\mathrm{NaOH}$ (300 mg, $7.50 \mathrm{mmol}$ ) was added as a powder to the stirred solution. The reaction system was left stirring at $50{ }^{\circ} \mathrm{C}$ for $7 \mathrm{~h}$, cooled to room temperature and extracted with distilled water $(2 \times$ $10 \mathrm{ml}$ ). $\mathrm{NaCl}$ was added to neutralize the aqueous solution, which was then extracted with $\mathrm{CH}_{2} \mathrm{Cl}_{2}(4 \times 15 \mathrm{ml})$. The resulting organic phase was dried over anhydrous sodium sulfate and concentrated under reduced pressure.

The final product was obtained as white solid dissolving the residue in excess of diethyl ether and collecting the formed precipitate by filtration under vacuum ( $97 \%$ yield). The epoxide moiety linked to the polymeric chain was evaluated by ${ }^{1} \mathrm{H}-\mathrm{NMR}$ analysis. ${ }^{1} \mathrm{H}$ NMR (400 MHz, $\mathrm{CDCl}_{3}$ ) $\delta: 3.57$ (s, 720H), 3.12-3.04 $(\mathrm{m}, 2 \mathrm{H}), 2.72(\mathrm{dd}, J=5.1,4.1 \mathrm{~Hz}, 2 \mathrm{H}), 2.54(\mathrm{dd}, J=5.0,2.7 \mathrm{~Hz}$, $2 \mathrm{H})$.

Synthesis of PEG-OH- $\mathbf{N}_{3} \mathbf{5}$. Ring-opening reaction of the diepoxide functionalized PEG occurred as proposed by Zhang and coworkers. ${ }^{44}$ Polymer 4 (800 $\left.\mathrm{mg}, 0.11 \mathrm{mmol}\right)$ was dissolved in DMF $(15 \mathrm{ml})$ and then sodium azide (130 $\mathrm{mg}, 2 \mathrm{mmol})$ and ammonium chloride $(216 \mathrm{mg}, 4 \mathrm{mmol}$ ) were added to the solution. The reaction system was stirred at $60{ }^{\circ} \mathrm{C}$ for $48 \mathrm{~h}$. The crude product was concentrated under reduced pressure and then precipitated into diethyl ether. The obtained solid was dissolved in $\mathrm{CH}_{2} \mathrm{Cl}_{2}$ and diethyl ether was added again to precipitate the final purified polymer (90\% yield). ${ }^{1} \mathrm{H}$ NMR (400 $\left.\mathrm{MHz}, \mathrm{CDCl}_{3}\right) \delta: 3.58(\mathrm{~s}, 720 \mathrm{H}), 3.28(\mathrm{~d}, J=5.5 \mathrm{~Hz}, 4 \mathrm{H})$.

Synthesis of activated PEG-rhodamine 6. The formation of stable bond between modified PEG 5 and the complex 3 carrying the mimetic drug was obtained through coppercatalyzed alkyne-azide cycloaddition (CuAAC). The polymer $\mathbf{5}$ $(250 \mathrm{mg}, 31.25 \mu \mathrm{mol})$ was dissolved in a solution of acetonitrile $(10 \mathrm{ml})$ and water $(4 \mathrm{ml})$, whereas the compound 3 (44 mg, 62.5 $\mu \mathrm{mol}$ ) was dissolved in acetonitrile $(3 \mathrm{ml})$. Therefore, the polymer solution was added dropwise to the other organic solution. To this system, copper iodide $(7 \mathrm{mg}, 37.5 \mu \mathrm{mol})$ and sodium ascorbate $(7.5 \mathrm{mg}, 37.5 \mu \mathrm{mol})$ were added. The reaction mixture was allowed to stir at $50{ }^{\circ} \mathrm{C}$ for $48 \mathrm{~h}$. Subsequently, it was cooled to room temperature, concentrated under reduced pressure and re-dissolved in distilled water. The purification of the product was performed through dialysis (membrane $M_{\mathrm{w}}$ cutoff $=3.5$ $\mathrm{kDa}$ ) against distilled water (2 l). Dialysis occurred for two days, with daily replacement of the aqueous media.

The resulting system was lyophilized, giving a purple solid. This intermediate was labelled as compound 5-R. Finally, the latter $(30 \mathrm{mg}, 4 \mu \mathrm{mol})$ was dissolved in acetonitrile $(5 \mathrm{ml})$ and CDI $(0.97 \mathrm{mg}, 6 \mu \mathrm{mol})$ was added. The reaction mixture was left stirring at $40{ }^{\circ} \mathrm{C}$ for $70 \mathrm{~h}$. Successively, the solvent was evaporated under vacuum and the residue was precipitated into diethyl ether. The formed solid was collected and dried by vacuum filtration and characterized by NMR analysis and gel permeation chromatography (ESI $\dagger$ ).

Synthesis of PEI-Cy5 7. The synthesis of PEI bond to the dye Cy5-azide required two steps: the first one was the functionalization of PEI with alkyne moieties and the second one was the click reaction (CuAAC) between the polymer and the dye. PEI was modified with triple bonds using propargyl bromide, as described in our previous work, ${ }^{45}$ using a molar ratio
PEI : propargyl bromide $1: 5$. The formation of triazole using click strategy was performed as follows: functionalized PEI (10 mg, $4 \mu \mathrm{mol}$ ) was dissolved in distilled water $(2 \mathrm{ml})$ and a solution $(200 \mu \mathrm{l}, 0.4 \mu \mathrm{mol})$ of Cy5-azide in DMSO $\left(2 \mathrm{mg} \mathrm{ml}^{-1}\right)$ was added to the system. Copper iodide $(0.02 \mathrm{mg}, 0.2 \mu \mathrm{mol})$ and sodium ascorbate $(0.02 \mathrm{mg}, 0.2 \mu \mathrm{mol})$ were added to the mixture and the latter was heated to $50{ }^{\circ} \mathrm{C}$ for $24 \mathrm{~h}$, under stirring. Then, the resulting system was dialyzed against distilled water (2 l), using dialysis membrane with $M_{\mathrm{w}}$ cutoff $=500 \mathrm{Da}$, for 2 days, with daily replacement of the aqueous media. The polymer was collected after lyophilization and ${ }^{1} \mathrm{H}$-NMR spectrum confirmed the polymer functionalization.

\section{Nanogel formation}

Nanogels were performed referring to the modified emulsificationevaporation method. ${ }^{46}$ Activated PEG-rhodamine 6 (28 mg, 2.88 $\mu \mathrm{mol})$ was dissolved in $\mathrm{CH}_{2} \mathrm{Cl}_{2}(1 \mathrm{ml})$, whereas modified PEI-Cy5 7 (5 mg, $1.92 \mu \mathrm{mol})$ was added to distilled water $(2 \mathrm{ml})$ until complete dissolution.

The organic solution was added dropwise, under vigorous stirring, to the aqueous one and the resulting system was sonicated for $30 \mathrm{~min}$. $\mathrm{CH}_{2} \mathrm{Cl}_{2}$ was evaporated and the mixture left stirring for $17 \mathrm{~h}$ at room temperature. Formed nanogels were purified by dialysis (membrane $M_{\mathrm{w}}$ cutoff $=3.5 \mathrm{kDa}$ ) against distilled water (2 l) and lyophilized. They were characterized by ${ }^{1} \mathrm{H}$-NMR and FT-IR spectra. Moreover, the diameter and the shape of these nanostructures were evaluated by DLS and AFM analyses.

\section{Rhodamine release from nanogels}

Drug release mechanism was investigated in two different release environments: the first one was a phosphate buffer saline solution (PBS) at $\mathrm{pH} 7.4$, whereas the second one was a glutathione (GSH) solution $5 \mathrm{mM}$. Obtained nanogels $(5 \mathrm{mg})$ were separately placed in excess of PBS and GSH solution $(1 \mathrm{ml})$ and stored at $37^{\circ} \mathrm{C}$. At defined interval of time, for each sample, aliquots $(3 \times 100 \mu \mathrm{l})$ of the released media were collected for UV-vis measurements and substituted, respectively, with the same volume of fresh PBS or GSH solution, in order to avoid mass-transfer equilibrium with the surrounding release environment. The released amount of mimetic drug was spectrophotometrically measured at $570 \mathrm{~nm}$ and determined referring to the standard calibration curve for amine-rhodamine 1 (ESI $\dagger$ ). The percentage of the released rhodamine was defined as the ratio of the released absolute amount in the aqueous media to the sum of the total amounts of the released and unreleased mimetic drug. All these experiments were repeated 3 times and the results were averaged.

\section{Biological evaluation: cell-mediated drug release}

Cell culture. Primary cultures of microglia were obtained from the spinal cord of 13 day-old C57 BL/6N mouse embryos as previously described. ${ }^{47}$ Briefly, spinal cords were dissected, exposed to DNAse and trypsin and centrifuged through a BSA cushion. 
Cells obtained at this step were a mixed neuron/glia population and underwent centrifugation through a $6 \%$ iodixanol (OptiPrep ${ }^{\mathrm{TM}}$ ) cushion to separate large neurons from glial cells. The glial fraction was plated at a density of 25000 cells per $\mathrm{cm}^{2}$ into $75 \mathrm{~cm}^{2}$ flasks, previously pre-coated with poly-L-lysine. Isolated microglia were obtained from flasks containing confluent mixed glial cultures after overnight shaking at $275 \mathrm{rpm}$ in incubators. The supernatants (containing microglia) were collected and seeded at a density of 40000 cells per $\mathrm{cm}^{2}$ into 24 -well plates. NGs $(0.05 \%$ weight/volume) were then added to cell cultures up to 3 days.

Cytocompatibility. After 5 days of culturing, the cytotoxicity of nanogels was evaluated by performing an MTS assay and level of lactate dehydrogenase $(\mathrm{LDH})$ release. ${ }^{48}$ The absorbance was measured at 570 and $490 \mathrm{~nm}$ respectively, and the results were compared with that of the control wells to determine relative cell viability.

Microscope analysis: in vitro drug release. Fluorescence was acquired at $10 \times$ objective magnification (BX61, Olympus, Japan) using a 16 bit high-resolution camera (Fluoview II, Olympus, Japan) and an appropriate filter cube avoiding cross talk of signals between different fluorochromes. Fluorescent staining was quantified using the signal segmentation plugin of ImageJ software (http://www.rsbweb.nih.gov).
Statistical analysis. Where applicable, experimental data were analyzed using Analysis of Variance (ANOVA) and Tukey post-test. Statistical significance was set to $p$ value $<0.05$. Results are presented as mean value \pm standard deviation.

\section{Results and discussion}

\section{Chemical characterization}

PEG functionalization: rhodamine-disulfide linkage. The design of sensitive systems to biological stimuli appears as a leading strategy to achieve controlled drug release dependent on intracellular trigger mechanism. Indeed, the synthesis of covalent bonds readily broken by defined biomolecules allows to obtain a drug release that is not only dependent on the diffusion coefficient of the molecules through the polymeric matrix, but it is influenced by the characteristics of chemical binding between the loaded drug and the polymeric network. This permits to interfere into the drug release kinetics, without any external complementary assistants and allowing free drug level within a desired range over a long period. PEG functionalization with a S-S linker carrying rhodamine is proposed as a technique to achieve this aim. The disulfide bond has found increasing attention for the application on controlled drug delivery systems, due to its high redox sensibility. ${ }^{49}$ It could be broken by thiol

A<smiles>C#CCNCC#CCBr</smiles>

B<smiles>C#CCOCCSSCCO</smiles><smiles>C#CCOCCSSCCOC(=O)n1ccnc1</smiles>

$+$<smiles>CCN(CC)C1=CC23CC(C1)C1(CCN2C(=O)c2ccccc21)c1ccc(N(CC)CC)cc1O3</smiles>

1

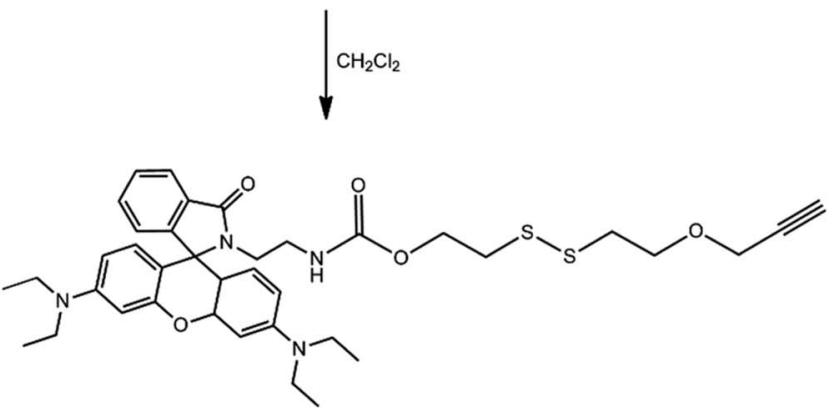

Fig. 1 Steps of synthesis of disulfide derivative grafting on one side the terminal alkyne group (A) and on the other side rhodamine (B). 
compounds, such as cysteine and glutathione, commonly present in human cells. ${ }^{\mathbf{5 0 , 5 1}}$ The polymer modification was performed through the synthesis of a system where the only cleavable bond was $\mathrm{S}-\mathrm{S}$ bridge. In detail, one terminal -OH group of the disulfide-functional reagent was chemically modified with alkyne moiety (Fig. 1A), whereas its other hydroxyl group reacted with amine modified rhodamine (Fig. 1B).

In this way, the mimetic drug was linked to the $\mathrm{S}-\mathrm{S}$ bridge structure, which in turn was grafted to a triple bond, needed for the formation of a stable and non-cleavable linkage with PEG. Obtaining the compound 3 necessarily involved the purification of the compound 2 (NMR spectrum visible in Fig. S1 $\dagger$ ) by chromatographic technique in order to separate the correct product carrying only one alkyne functionality and one $-\mathrm{OH}$ group.

Indeed, the hydroxyl groups of 2-hydroxyethyl disulfide showed the same reactivity, due to its molecular symmetry, and the foresight to use a molar ratio disulfide: propargyl between the reagents equal to $1: 1$, in order to potentially involve only<smiles>CCC1CO1</smiles>
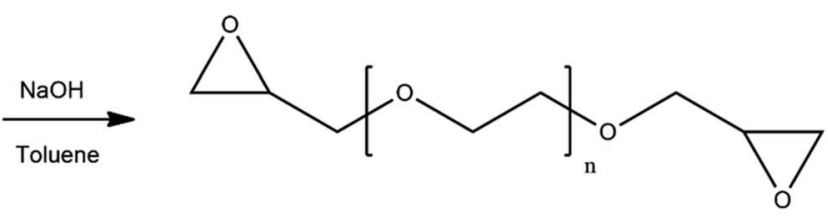

4

Fig. 2 Synthesis of PEG with both terminal epoxide moieties.<smiles>CC(C)(CCOC(C)(C)CC1CO1)OCC1CO1</smiles>

4

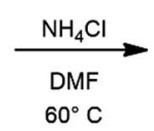

$60^{\circ} \mathrm{C}$

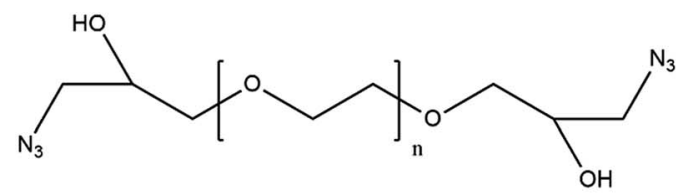

5

Fig. 3 Functionalization of PEG with azide groups. The reaction allowed restoring the hydroxyl groups of the polymer.

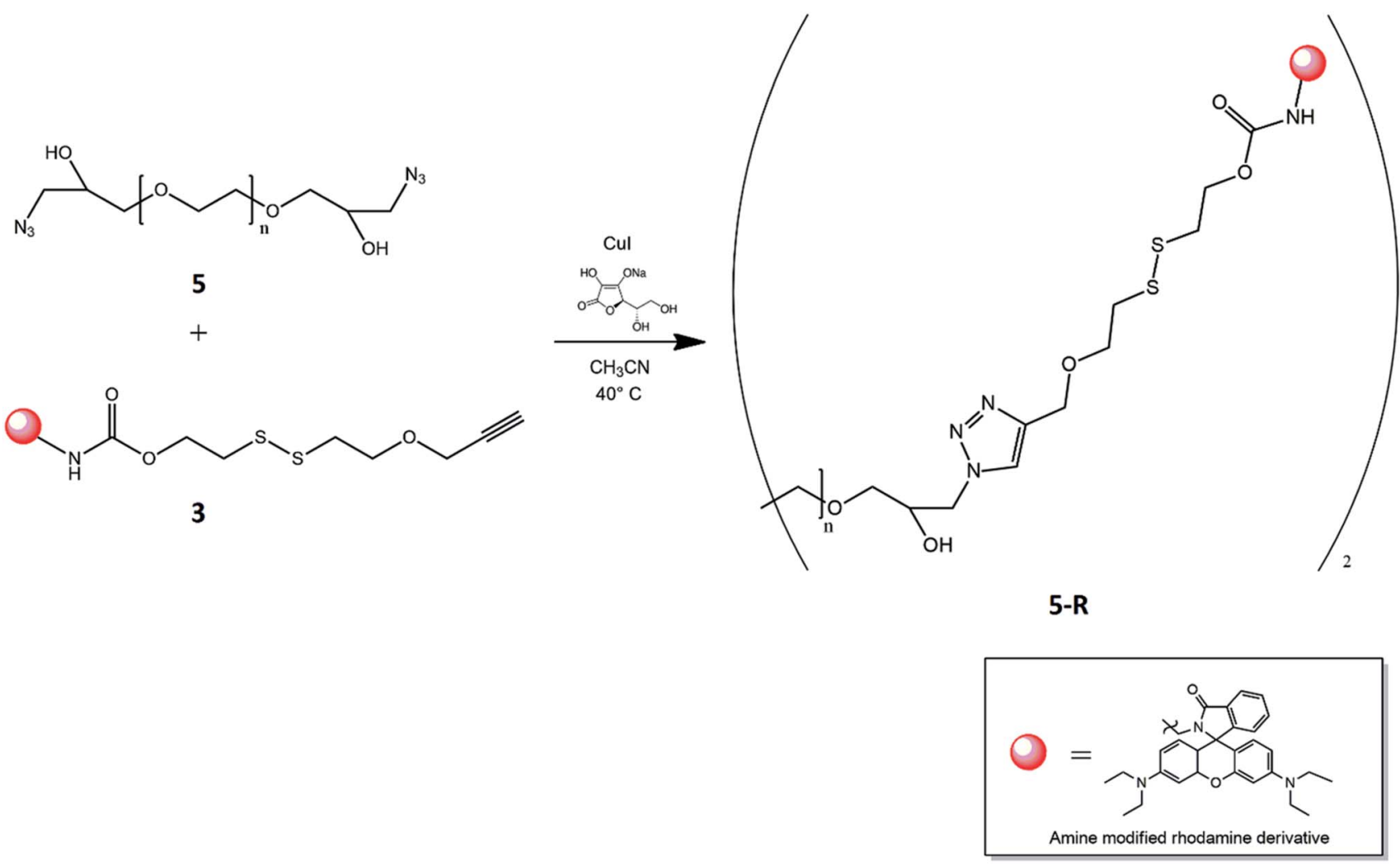

Fig. 4 Click reaction between modified PEG-OH-N 5 and rhodamine derivative 3 . 
one - $\mathrm{OH}$ group of each molecule in the reaction with the alkyne derivative, was not enough to produce the desired product because the formation of a mixture of mono-, bis-, or no functionalized system was obtained. The integral values of the characteristic signals of 2 in its ${ }^{1} \mathrm{H}$-NMR spectrum, confirmed the collection of the mono-functionalized product (ESI $\dagger$ ). The introduction of triple bond was justified by the need to graft the sensitive drug-disulfide linker system to the polymeric chain using copper-catalyzed azide alkyne cycloaddition (CuAAC). The formed triazole ring possesses a number of desirable features reported in the medicinal chemistry and, in particular, is stable under standard physiological conditions, which suits well for gene and drug delivery system. The use of click chemistry required the functionalization of PEG with azide moiety, that was performed in two steps. The first one, as illustrated in
Fig. 2, involved the preparation of the polymer with epoxide end groups, through reaction with epichlorohydrin. PEG functionalization was verified by ${ }^{1} \mathrm{H}-\mathrm{NMR}$ analysis (Fig. $\mathrm{S} 2 \dagger$ ), that showed the specific peaks of the epoxy ring at $3.12 \mathrm{ppm}$, $2.72 \mathrm{ppm}$ and $2.54 \mathrm{ppm}$, and then estimated according to the literature procedure: ${ }^{\mathbf{4 3}}$ resulting polymer was characterized by all hydroxyl terminal groups substituted by epoxide groups.

The second step, reported in Fig. 3, consisted in the ringopening reaction of di-epoxide PEG using sodium azide and ammonium chloride as a coordinating salt; ${ }^{52}$ in this case, ${ }^{1} \mathrm{H}$ NMR analysis revealed new signals related to the methylene group adjacent to azide group at $3.28 \mathrm{ppm}$, while the epoxide proton resonances disappeared (Fig. S3†). In this way, we introduced $-\mathrm{N}_{3}$ moiety and restored $-\mathrm{OH}$ groups at both PEG sides. The importance of the presence of hydroxyl groups was
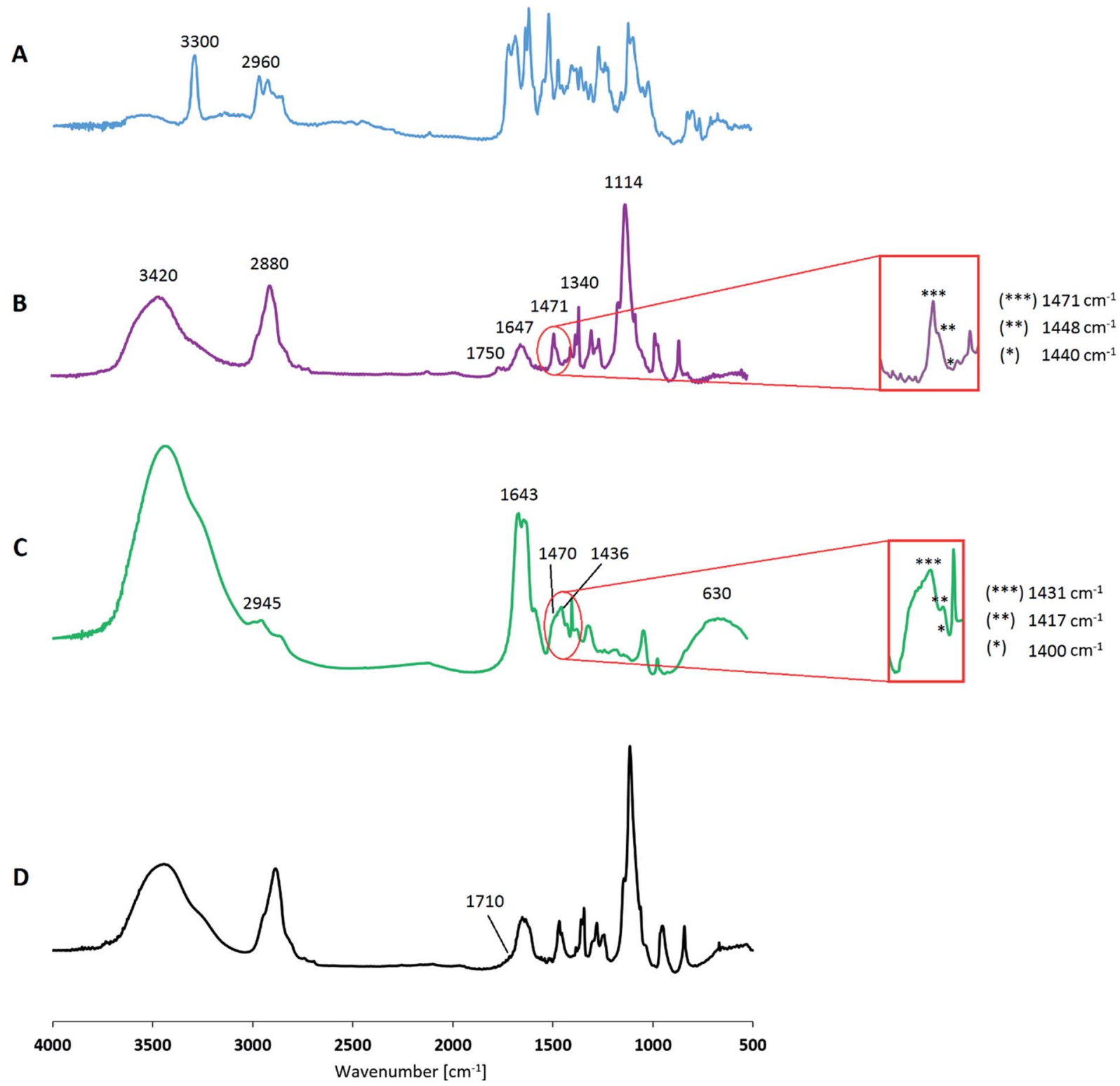

Fig. 5 (A) FT-IR spectrum of compound 3, (B) FT-IR spectrum of functionalized PEG 5-R, (C) FT-IR of functionalize PEI 7, (D) FT-IR spectrum of synthetized nanogels. 
related to their chemical modification with imidazole, essential for PEG-PEI nanogel synthesis.

Finally, the click reaction between PEG-OH- $\mathrm{N}_{3}, 5$, and disulfide bridge with rhodamine on one side and alkyne group on the other end, $\mathbf{3}$, was carried out with copper iodide as the catalyst, sodium ascorbate as reducing agent and a mixture of acetonitrile-water as the solvent (Fig. 4). According to the presence of two azide groups for each PEG chain, the used molar ratio between 5 and 3 was equal to $1: 2$, in order to ensure quantitatively the reaction. The disulfide functionalized PEG was purified by dialysis against distilled water to remove unreacted chemicals and salts. The formation of triazole was confirmed by its characteristic signal in ${ }^{1} \mathrm{H}$-NMR spectrum (Fig. S4 $\dagger$ ). Moreover the GPC chromatogram visible in Fig. S6 $\dagger$ reveals the presence of functonalized polymer.

Fig. 5B shows the FT-IR spectrum of the modified PEG, where the characteristic signals of triazole can be recognized at $1471 \mathrm{~cm}^{-1}, 1448 \mathrm{~cm}^{-1}, 1440 \mathrm{~cm}^{-1}$, as outlined in the figure. The broad peak around $3420 \mathrm{~cm}^{-1}$ corresponding to the stretching vibration of terminal $-\mathrm{OH}$ bonds, whereas the signals at 2880 $\mathrm{cm}^{-1}$ and at $1114 \mathrm{~cm}^{-1}$ are respectively due to the $\mathrm{C}-\mathrm{H}$ and $\mathrm{C}-\mathrm{O}-\mathrm{C}$ stretch of the polymer chain. Other characteristic PEG signals, related to the $\mathrm{C}-\mathrm{H}$ bending, are found in the wavenumbers range around $1470 \div 800 \mathrm{~cm}^{-1}$. In addition, in the range $1750 \div 700 \mathrm{~cm}^{-1}$ peaks related to rhodamine are detectable according to the signals of the FT-IR spectrum of compound 3 (Fig. 5A): this confirms that PEG is linked in a stable manner to the modified mimetic drug and it is still reflected in the absence of the alkyne signal at $3300 \mathrm{~cm}^{-1}$, which is, otherwise, clearly visible in the spectrum of compound 3. The latter also shows the characteristic stretching vibration of $\mathrm{C}=\mathrm{O}$ at $1715 \mathrm{~cm}^{-1}$, represented also in the spectrum of the functionalized PEG.

PEI functionalization: click with Cy5. PEI was modified using propargyl bromide in a feed ratio of $1: 5$ and the excess amount of the alkyne groups in comparison to polymer was used to ensure the reaction conversion. The percentage of linked propargyl moiety was evaluated referring to ${ }^{1} \mathrm{H}-\mathrm{NMR}$ spectrum: as illustrated in our previous work, ${ }^{45}$ the ratio among the integral value of the signal at $3.55 \mathrm{ppm}$, related to monomer propargyl derivative, and the peaks corresponding to PEI-block in the range $3.50-2.90 \mathrm{ppm}$, suggested that the functionalization degree of the polymer was $10 \%$. The signal corresponding to the $\mathrm{H}$ of alkyne was covered by the peak of the polymer chains. The resulting product reacted with Cy5- $\mathrm{N}_{3}$ using click strategy CuAAC (Fig. 6), in a similar manner as
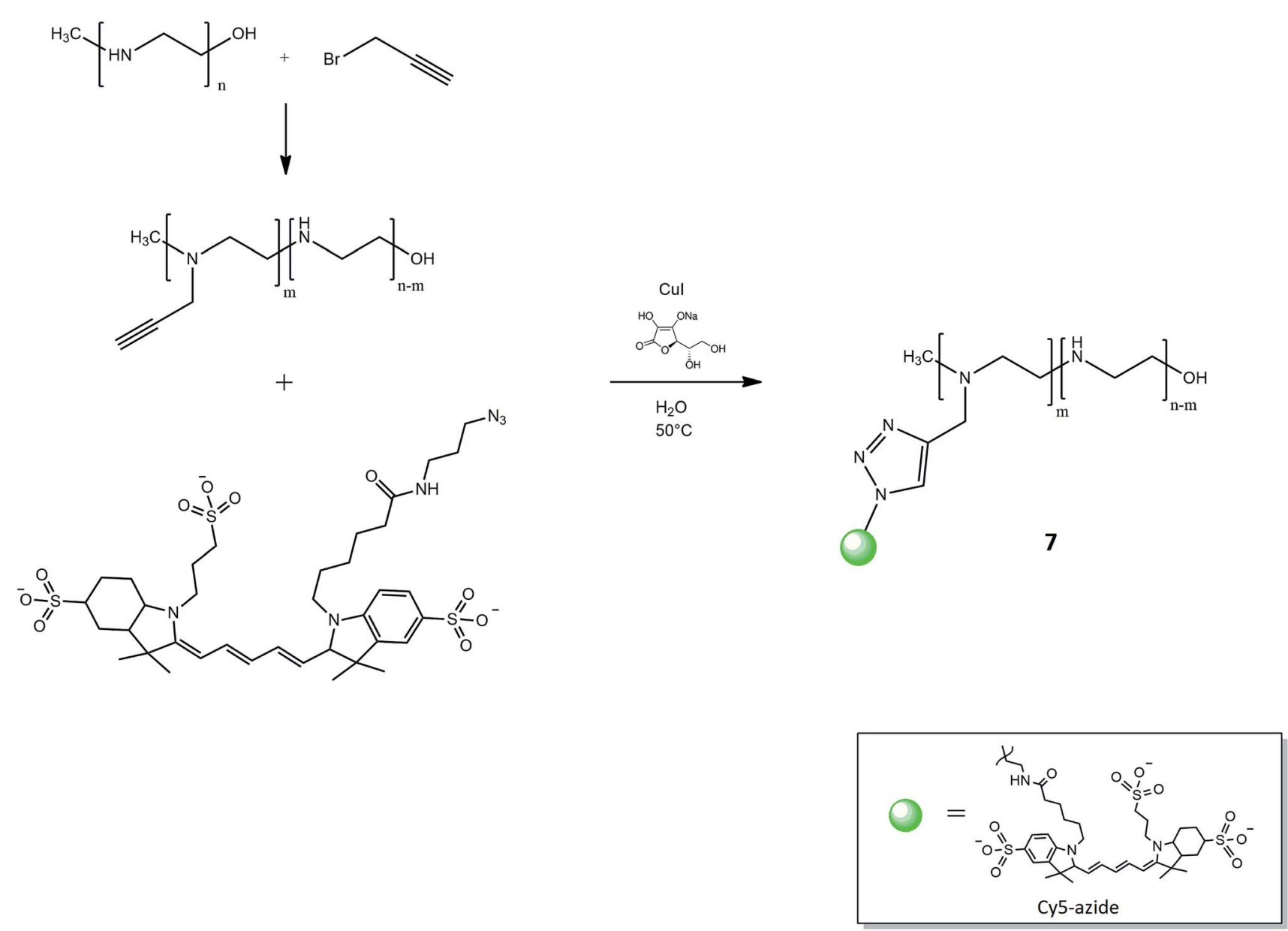

Fig. 6 Synthesis procedure of PEI linked through click strategy to dye Cy5. 
described in the previous section about the formation of triazole between PEG and disulfide derivatives.

PEI linked to Cy5 was collected after purification by dialysis to remove unreacted chemicals and avoid the separation of product as PEI complexes with copper. ${ }^{1} \mathrm{H}-\mathrm{NMR}$ spectrum showed the characteristic signal of triazole at $8.10 \mathrm{ppm}$ and FTIR spectrum sets out the corresponding peaks around 1470 $\mathrm{cm}^{-1}$. Fig. 5C also shows PEI peculiar signals: at $3240 \mathrm{~cm}^{-1}$ due to $\mathrm{N}-\mathrm{H}$ stretching, in the range $2945 \div 2820 \mathrm{~cm}^{-1}$ of $\mathrm{C}-\mathrm{H}$ stretching, at $1643 \mathrm{~cm}^{-1}$ representative of $\mathrm{N}-\mathrm{H}$ bending, at 1463 $\mathrm{cm}^{-1}$ related to $\mathrm{PEI} \mathrm{C}-\mathrm{H}$ bending and in the wavenumber range $1400 \div 900 \mathrm{~cm}^{-1}$ the peaks are due to $\mathrm{C}-\mathrm{N}$ stretching. According to the emission/absorbance of Cy5 dye, ${ }^{53}$ its corresponding signal is reported around $630 \mathrm{~cm}^{-1}$. PEI functionalization could occur at higher percentage of linked alkyne group and then of grafted Cy5, just increasing the amount of propargyl bromide involved in the corresponding reaction. However, our study suggests that a dye functionalization degree of $10 \%$ is satisfactory for ensuring the traceability of the final nanogel systems within cellular media. In addition, lower chemical modification of PEI chain allows maintaining its peculiar properties without any potential alterations, in particular the availability of amine moieties for the successive nanogel synthesis. Cy5 was chosen due to its functional detection in biological application; cyanine derivatives are characterized by the fact that absorbance and fluorescence wavelength can be controlled by polymethine bridge length: longer cyanines possess higher absorbance and emission wavelengths up to near infrared region. Cy5- $\mathrm{N}_{3}$ is fluorescent in the red region ( $\sim 650$ excitation, $670 \mathrm{~nm}$ emission) and its signal is detectable where many charge-coupled devices detectors have better sensitivity, and biological compounds have lower background. In this way, it is possible to mark the used polymer and also investigate its fate in the in vitro experiments.

\section{Nanogel composition}

Synthesis of biocompatible PEG-PEI nanogels was achieved by coupling of modified PEG 6 and PEI 7 using a modified emulsification-evaporation method. ${ }^{46}$ According to this procedure, the solution of activated PEG (grafting the disulfide bridgerhodamine system) in dichloromethane was emulsified in the aqueous solution of PEI (grafting Cy5) by sonication. After the completion of the cross-linking reaction, the organic solvent was removed under vacuum, and nanogel was allowed to form in the aqueous medium (Fig. 7). The growing stage completed the rearrangement of linked polymers, according to the chain entanglements in the forming nanogel networks. The resulting suspension was subjected to purification via dialysis to remove by-products and unreacted polymers.

The effective synthesis of nanogels was verified by ${ }^{1} \mathrm{H}-\mathrm{NMR}$ data, where the signals at $4.12 \mathrm{ppm}$ and at $3.38 \mathrm{ppm}$ correspond, respectively, to the two methylene protons of PEG and PEI monomer forming the carbamate bond (Fig. S5 $\dagger$ ). This confirmed the cross-linking between the two polymer chains. The composition of this nanostructures was estimated in terms of molar ratio between the polymers, considering the integral values of the PEG (range 3.80-3.40 ppm) and PEI (range 2.85$0.80 \mathrm{ppm}$ ) chains signals and it turned out to be PEG : PEI $1.5: 1$. FT-IR spectrum reported in Fig. 5D shows the distinctive
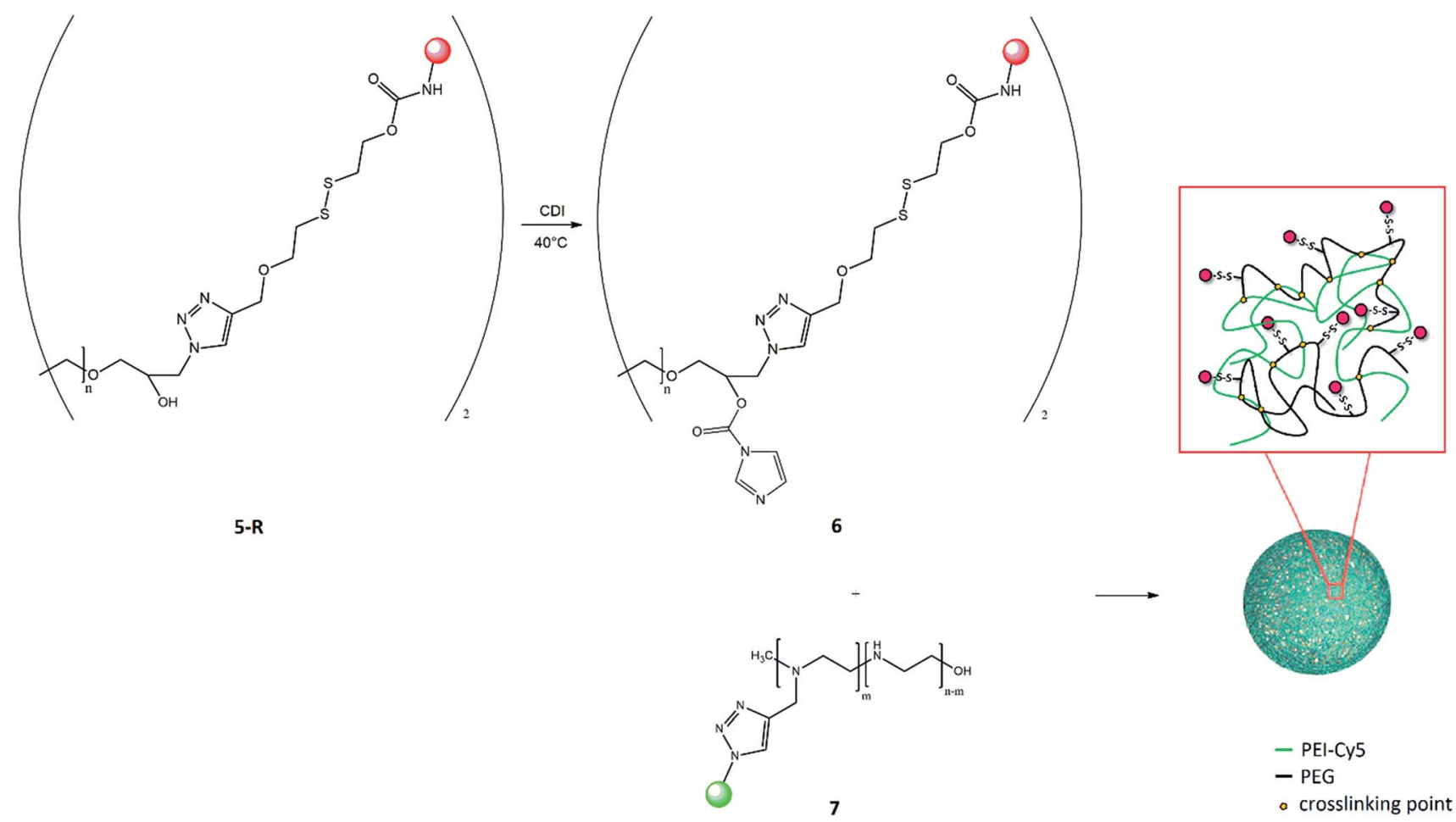

Fig. 7 Scheme of nanogel synthesis. 
signals of the polymers and their corresponding functionalizations according to the FT-IR spectra of modified PEG (Fig. 5B) and PEI (Fig. 5C); in particular, the presence of signal at about $1710 \mathrm{~cm}^{-1}$ is representative of $\mathrm{C}=\mathrm{O}$ stretching related to the carbamate linkage.

\section{Physical characterization}

One of the most important issues in the field of nanoscience is the size effect on the biodistribution, kinetic of release, and cellular uptake of nanoparticles. ${ }^{54}$ Therefore, the investigation of nanogel dimensions is necessary to design system able to be internalized through active or passive uptake. Dynamic light scattering (DLS) is a widely used technique for nanoparticle size and $\zeta$-potential determination in suspension. The measured hydrodynamic diameter represents the dimension of the polymeric sample together with layer of surface-bound solvent. Recorded DLS data provide nanogel average diameter equal to $462 \mathrm{~nm}$ (polydispersity index, PDI $=0.066$ ) and a surface charge of $+21.8 \mathrm{mV}$. The positive value of $\zeta$-potential indicates that

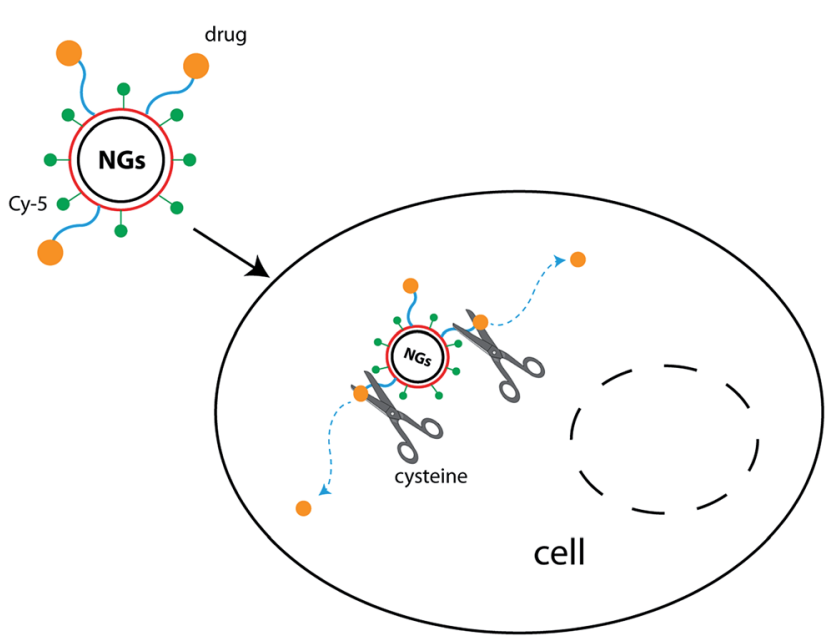

Fig. 8 Scheme of rhodamine release within a cell, due to the reduction of $\mathrm{S}-\mathrm{S}$ bond by thiol compound. nanogels are characterized by a positive surface charge, probably due to the ability of PEI, although alkyne functionalization, to preserve part of its positive charge in the final polymeric network. Size distribution may be quantified by using atomic force microscopy (AFM) analysis, obtaining additional information about the morphology. In this case, the obtained size is $250 \mathrm{~nm}$ (data not shown). The size of the nanogels observed by AFM was less than those measured using DLS.

This variation between AFM and DLS measurements is justifiable considering the difference in the sample processing: in DLS, the slight increase in size is due to the nanogel swelling behaviour in aqueous solution. This problem was not present with hydrophobic polymeric nanoparticles synthesized by our group and presented in previous work. ${ }^{55}$ In that case, the complete accordance between AFM and DLS was due to the fact that in that system swelling phenomenon was negligible. Therefore, obtained results suggested that nanogels presented particle diameter and surface charge within the range useful to promote cellular internalization, according to the guideline in the rational design of drug nanocarriers with maximized therapeutic efficacy. ${ }^{25}$

\section{Drug release mechanism}

The efficacy of synthetized nanogels as selective drug delivery systems was investigated performing the rhodamine release experiments in two different media, at $37^{\circ} \mathrm{C}$. The first one was GSH solution $5 \mathrm{mM}$, prepared in a $\mathrm{pH} 7.4$ phosphate buffer and representative of the average intracellular glutathione concentration in human body; ${ }^{49}$ whereas, the second one was PBS solution, chosen as a reference, in order to evaluate the potential GSH-responsive effect of our nanosystems. The aim was the evaluation of the interactions between a disulfide bond and a thiol compound: the first one is slightly degradable under physiological conditions but can be quickly cleaved in a highly reductive environment within the cells, achieving controlled intracellular rapid drug release. A schematic representation of the rhodamine release mechanism that could occur within cellular membrane is reported in Fig. 8: the S-S reduction could

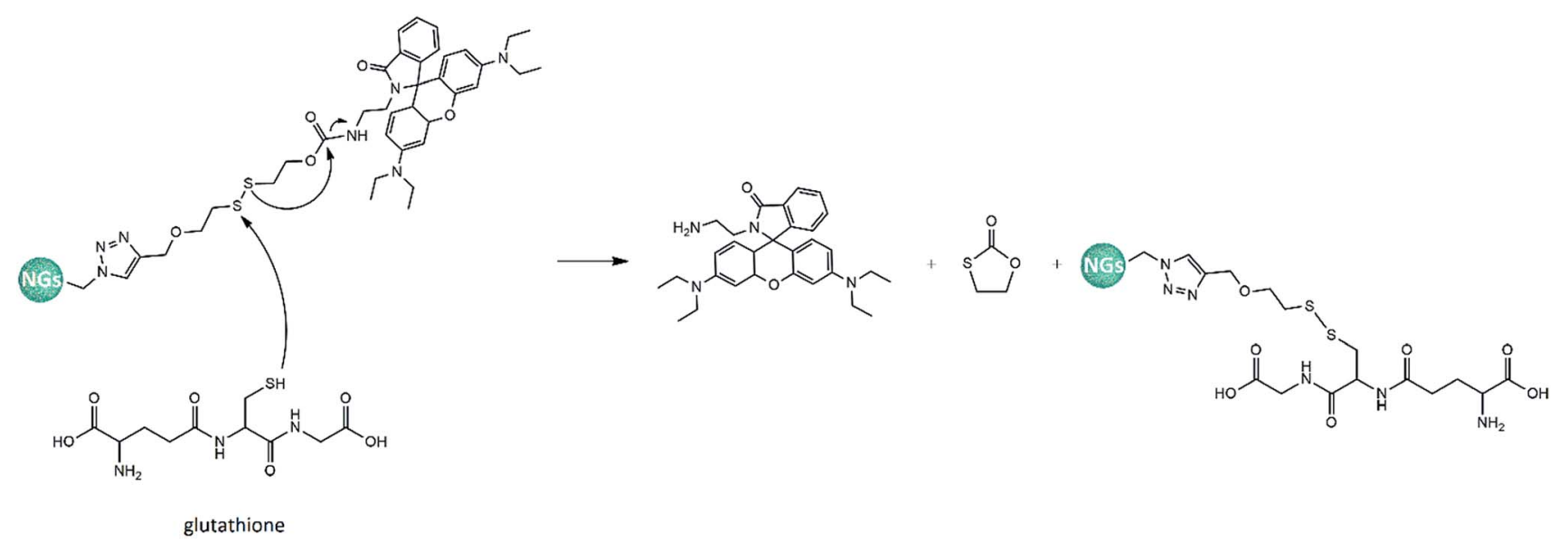

Fig. 9 Mechanism of rhodamine release from nanogel system in presence of GSH. 
be performed by GSH or cysteine cell component (both present -SH group and interact in a similar manner). ${ }^{56,57}$

About thiol-sensing in biological samples, GSH has a leading role because it is the most abundant thiol in cells. ${ }^{51,58}$ The percentage of rhodamine released from the nanogels was defined

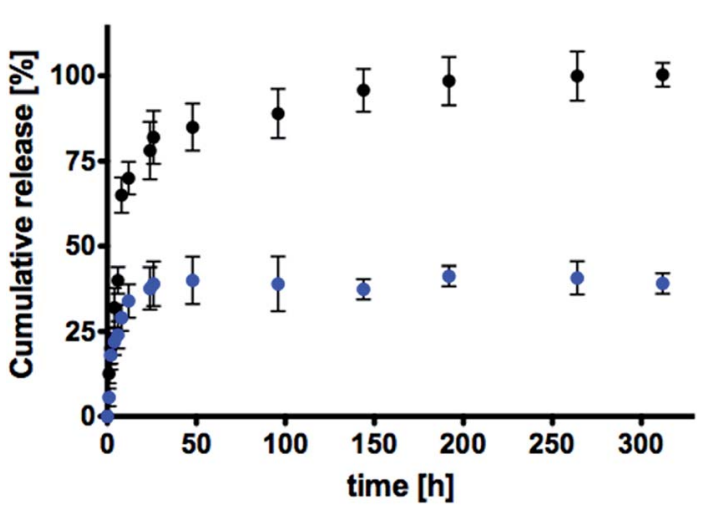

Fig. 10 Release profile of rhodamine delivered from nanogels in GSH media ( $\bullet$, black) and in PBS solution $(\bullet$, blue). The values are calculated as a percentage with respect to the total mass loaded (mean value \pm standard deviation is plotted). as the ratio between the release amount in the aqueous media and the total amount linked to the polymeric network. The spectrophotometrical evaluation of escaped rhodamine was performed referring the calibration curve of the mimetic drug as amine modified rhodamine 1: the disulfide cleavage in the redoxresponsive environment allowed the release of $\mathbf{1}$, as showed in Fig. 9, without any other linked functionalizations (which, otherwise, are needed to the synthesis of the final sensitive nanogels), that could distort the UV-vis measurements.

Fig. 10 shows the release profiles in GSH (in black) and in PBS (in blue) solutions. It is well visible that rhodamine release is faster in media containing the thiol compound and it is completed within $150 \mathrm{~h}$. Release profile associated to the physiological PBS media is prolonged for a much longer period, underling that the key difference between the two release mechanisms is related to the presence or absence of GSH. In particular, it is evident that the synthetized nanogels are thiolsensitive and the disulfide bridge plays a leading role in the development of redox-responsive nanogels. In these systems, the release of rhodamine occurred due to the selective reduction of S-S moiety caused by GSH that is the driving force influencing the release kinetic. In addition, considering that used GSH concentration is representative of the thiol amount

\section{A}
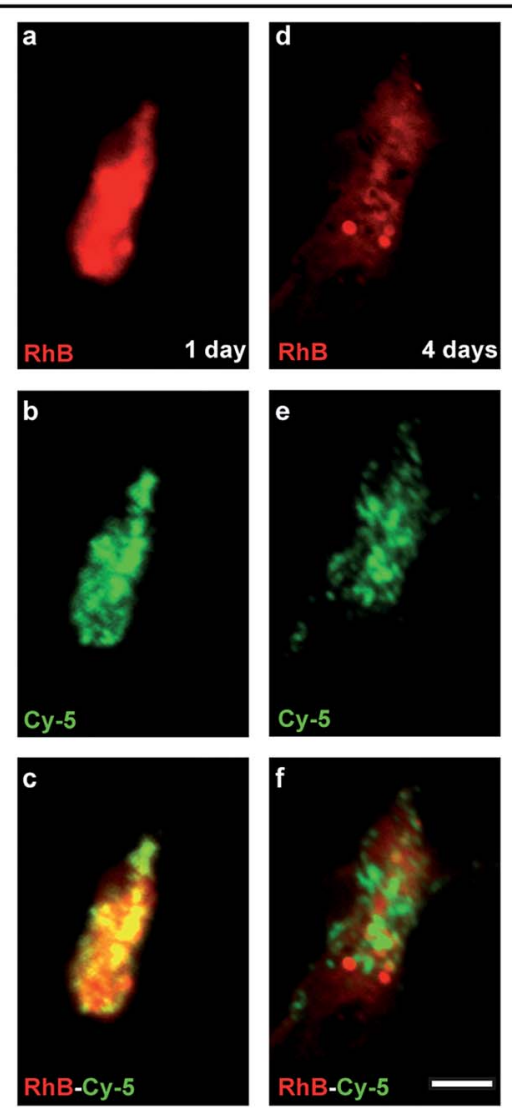

B

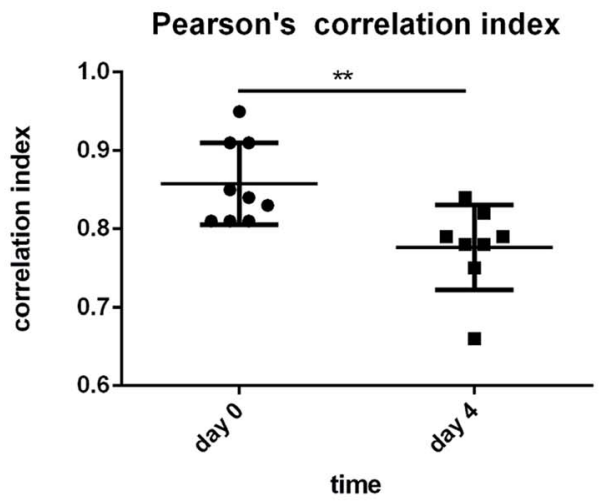

C

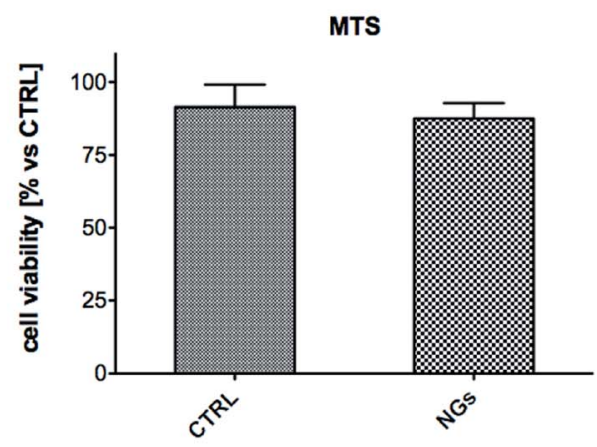

Fig. 11 (A) Microglial cells show a prevalent colocalized signal of Cy5 and RhB in the cytosol after $24 \mathrm{~h}$ of exposure (a-c). A markedly diffused signal of RhB is evident in the cytosol after 4 days from the NG internalization ( $d-f)$. Scale bar $=50 \mu m$. (B) Representative colocalization analysis by Pearson's coefficient shows a different colocalization of NPs (Cy-5, green) with RhB (red) after 1 day and after 4 days. $p$ value** $=p<0.001$ (C) Microglia viability after incubation with nanogels for 4 days. The columns represent the mean $\pm S D$. 
detectable within cells, produced nanostructures seemed to be a promising tool to achieve a sensitive drug release caused only by common intracellular compounds, without any other external stimuli. In physiological environment without GSH, released rhodamine occurred with lower delivery rate, maintaining $70 \%$ of loaded mimetic drug still linked to the nanogel network at 14 days. In this case, the release was not caused by chemical interaction with GSH, but due to the progressive degradation of the disulphide bond in physiological conditions, considering its moderate instability towards the electrophilic and nucleophilic nature of polar solvents. ${ }^{59}$

The obtained results allow to state that the design of a disulfide linker make it possible to release a drug within intracellular environment due to the simple interactions with cell components, whereas an extracellular media (such as a PBS solution) decreases its susceptibility to reduction. In this way, the developed nanostructures could be considered useful for further investigations of intracellular drug release such as hydrophilic analgesic and anti-inflammatory drugs that are characterized by carboxyl terminal group, steric hindrance and resemblance in a similar manner to rhodamine structure (examples are: fenoprofen, diflunisal, mefenamic acid or ketorolac).

\section{In vitro cell-selective drug release}

To further understand whether polymeric NGs were able to deliver linked compounds into the cytosol of microglia we observed release profile of $\mathrm{RhB}$ (as drug mimetic) from Cy5 decorated nanogels.

The colocalization of single fluorescent Cy5-positive NGs (pseudocolor green) loaded with RhB (pseudocolor red) showed that the mimetic drug was efficiently encapsulated (Fig. 11A). To evaluate the rhodamine delivery by NGs in vitro the nanodevices were incubated for $24 \mathrm{~h}$ with microglial cells. At this time of analysis, microglia showed clusterized NGs in the cytosol with a colocalized Cy5 and RhB signals (Fig. 11Ac). After 4 days of incubation, a markedly diffused signal of $\mathrm{RhB}$ was revealed in the cytosol of the microglial cells and it was only partially colocalized with Cy5 (Fig. 11Ad and e).

This quantitatively evaluated by Pearson's correlation index, where rhodamine signal was more widespread diffused within the cytosol, compared to Cy5-positive NGs (Fig. 11B). Furthermore, we evaluated the biocompatibility of internalized NGs in microglial cell colture by MTS assay. Nanogel internalization did not affect microglia cell viability up to 4 days compared to microglia not exposed to the polymeric systems (Fig. 11C). To understand whether internalized NGs affected the integrity of cellular membranes we measured the level of lactate dehydrogenase $(\mathrm{LDH})$ released (Fig. $\mathrm{S7} \dagger$ ) in the culture medium. No detectable amount of $\mathrm{LDH}$ release was revealed underlining the biocompatibility of this colloidal system.

\section{Conclusions}

In this work, we investigated the possibility to carry hydrophilic molecules within nanogels towards specific target and without losing the drugs content in body fluids. Indeed, the nanogel traceability was successfully performed through a one-step CuAAC click chemistry involving PEI and Cy5 dye. Then, to improve drug delivery performances, we introduced a sensitive cleavable bond (disulfide) between polymeric chains and drug molecules in order to create a selective drug delivery vehicle. NGs were internalized by microglia, without detectable toxic effect. In vitro studies showed a selective drug release within the cell cytosol of activated microglia confirming the efficacy of this tool. The incorporation of these types of linkers reduced the drug escape to the surrounding environment compared to systems where solute's release is only driven by a pure Fickian diffusion mechanism. In conclusion, the approach proposed in this work is a potential system to provide benefit in different human neurologic pathologies opening new perspectives to the inflammatory treatment in the central nervous system, through the modulated drug uptake and release of activated microglia.

\section{References}

1 L. Florez, C. Herrmann, J. M. Cramer, C. P. Hauser, K. Koynov, K. Landfester, D. Crespy and V. Mailänder, Small, 2012, 8, 2222-2230.

2 J. Nicolas, S. Mura, D. Brambilla, N. Mackiewicz and P. Couvreur, Chem. Soc. Rev., 2013, 42, 1147-1235.

3 W. Liu, W. Zhang, X. Yu, G. Zhang and Z. Su, Polym. Chem., 2016, 7, 5749-5762.

4 I. Elliott Donaghue and M. S. Shoichet, Acta Biomater., 2015, $25,35-42$.

5 F. Rossi, G. Perale, S. Papa, G. Forloni and P. Veglianese, Expert Opin. Drug Delivery, 2013, 10, 385-396.

6 Y.-C. Kuo and H.-F. Ko, Biomaterials, 2013, 34, 4818-4830.

7 I. Canton and G. Battaglia, Chem. Soc. Rev., 2012, 41, 27182739.

8 M. Durán-Lobato, B. Carrillo-Conde, Y. Khairandish and N. A. Peppas, Biomacromolecules, 2014, 15, 2725-2734.

9 L. A. Sharpe, A. M. Daily, S. D. Horava and N. A. Peppas, Expert Opin. Drug Delivery, 2014, 11, 901-915.

10 T. Ramasamy, Z. S. Haidar, T. H. Tran, J. Y. Choi, J. H. Jeong, B. S. Shin, H. G. Choi, C. S. Yong and J. O. Kim, Acta Biomater., 2014, 10, 5116-5127.

11 S. K. Mann, A. Dufour, J. J. Glass, R. De Rose, S. J. Kent, G. K. Such and A. P. R. Johnston, Polym. Chem., 2016, 7, 6015-6024.

12 V. Mailänder and K. Landfester, Biomacromolecules, 2009, 10, 2379-2400.

13 G. Villaverde, A. Baeza, G. J. Melen, A. Alfranca, M. Ramirez and M. Vallet-Regi, J. Mater. Chem. B, 2015, 3, 4831-4842.

14 T. C. Johnstone, K. Suntharalingam and S. J. Lippard, Chem. Rev., 2016, 116, 3436-3486.

15 B. Karagoz, L. Esser, H. T. Duong, J. S. Basuki, C. Boyer and T. P. Davis, Polym. Chem., 2014, 5, 350-355.

16 A. E. Arnold, P. Czupiel and M. Shoichet, J. Controlled Release, 2017, DOI: 10.1016/j.jconrel.2017.02.019.

17 W. L. Tung, S. H. Hu and D. M. Liu, Acta Biomater., 2011, 7, 2873-2882. 
18 Y. Tian, S. Bian and W. Yang, Polym. Chem., 2016, 7, 19131921.

19 S. Papa, F. Rossi, R. Ferrari, A. Mariani, M. De Paola, I. Caron, F. Fiordaliso, C. Bisighini, E. Sammali, C. Colombo, M. Gobbi, M. Canovi, J. Lucchetti, M. Peviani, M. Morbidelli, G. Forloni, G. Perale, D. Moscatelli and P. Veglianese, ACS Nano, 2013, 7, 9881-9895.

20 S. Papa, I. Caron, E. Erba, N. Panini, M. De Paola, A. Mariani, C. Colombo, R. Ferrari, D. Pozzer, E. R. Zanier, F. Pischiutta, J. Lucchetti, A. Bassi, G. Valentini, G. Simonutti, F. Rossi, D. Moscatelli, G. Forloni and P. Veglianese, Biomaterials, 2016, 75, 13-24.

21 J. Meng, V. Agrahari and I. Youm, Journal of Neuroimmune Pharmacology, 2017, 12, 84-98.

22 M. Yu, X. Jie, L. Xu, C. Chen, W. Shen, Y. Cao, G. Lian and R. Qi, Biomacromolecules, 2015, 16, 2588-2598.

23 S. S. Minami, B. Sun, K. Popat, T. Kauppinen, M. Pleiss, Y. Zhou, M. E. Ward, P. Floreancig, L. Mucke, T. Desai and L. Gan, J. Neuroinflammation, 2012, 9, 22.

24 E. Nance, F. Zhang, M. K. Mishra, Z. Zhang, S. P. Kambhampati, R. M. Kannan and S. Kannan, Biomaterials, 2016, 101, 96-107.

25 C. He, Y. Hu, L. Yin, C. Tang and C. Yin, Biomaterials, 2010, 31, 3657-3666.

26 S. R. Cerqueira, J. M. Oliveira, N. A. Silva, H. Leite-Almeida, S. Ribeiro-Samy, A. Almeida, J. F. Mano, N. Sousa, A. J. Salgado and R. L. Reis, Small, 2013, 9, 738-749.

27 S. Kabu, Y. Gao, B. K. Kwon and V. Labhasetwar, J. Controlled Release, 2015, 219, 141-154.

28 H. Zou, Z. Wang and M. Feng, J. Controlled Release, 2015, 214, 121-133.

29 J. McMasters and A. Panitch, Acta Biomater., 2017, 49, 78-88.

30 E. Mauri, F. Rossi and A. Sacchetti, Mater. Sci. Eng., C, 2016, 61, 851-857.

31 C. Porsch, Y. Zhang, M. I. Montañez, J. M. Malho, M. A. Kostiainen, A. M. Nyström and E. Malmström, Biomacromolecules, 2015, 16, 2872-2883.

32 M. Li, Z. Tang, H. Sun, J. Ding, W. Song and X. Chen, Polym. Chem., 2013, 4, 1199-1207.

33 E. L. Schneider, J. Henise, R. Reid, G. W. Ashley and D. V. Santi, Bioconjugate Chem., 2016, 27, 1210-1215.

34 K. Ulbrich, K. Holá, V. Šubr, A. Bakandritsos, J. Tuček and R. Zbořil, Chem. Rev., 2016, 116, 5338-5431.

35 D. Ossipov, S. Kootala, Z. Yi, X. Yang and J. Hilborn, Macromolecules, 2013, 46, 4105-4113.

36 K. Vulic and M. S. Shoichet, J. Am. Chem. Soc., 2012, 134, 882-885.

37 C. L. Modery-Pawlowski, A. M. Master, V. Pan, G. P. Howard and A. Sen Gupta, Biomacromolecules, 2013, 14, 910-919.
38 G. Reina, S. Orlanducci, C. Cairone, E. Tamburri, S. Lenti, I. Cianchetta, M. Rossi and M. L. Terranova, J. Nanosci. Nanotechnol., 2015, 15, 1022-1029.

39 J. F. Quinn, M. R. Whittaker and T. P. Davis, Polym. Chem., 2017, 8, 97-126.

40 M. Bilzer and B. H. Lauterburg, Eur. J. Clin. Invest., 1991, 21, 316-322.

41 J. Alam, T. H. Keller and T. P. Loh, Chem. Commun., 2011, 47, 9066-9068.

42 L. Li, X. Wang, J. Yang, X. Ye and C. Wu, Macromolecules, 2014, 47, 650-658.

43 M. Teodorescu, B. Cursaru, P. Stanescu, C. Draghici, N. D. Stanciu and D. M. Vuluga, Polym. Adv. Technol., 2009, 20, 907-915.

44 B. Zhang, H. Zhang, R. Elupula, A. M. Alb and S. M. Grayson, Macromol. Rapid Commun., 2014, 35, 146-151.

45 E. Mauri, I. Moroni, L. Magagnin, M. Masi, A. Sacchetti and F. Rossi, React. Funct. Polym., 2016, 105, 35-44.

46 S. Vinogradov, E. Batrakova and A. Kabanov, Colloids Surf., B, 1999, 16, 291-304.

47 M. De Paola, A. Mariani, P. Bigini, M. Peviani, G. Ferrara, M. Molteni, S. Gemma, P. Veglianese, V. Castellaneta, V. Boldrin, C. Rossetti, C. Chiabrando, G. Forloni, T. Mennini and R. Fanelli, Mol. Med., 2012, 18, 971-981.

48 S. Papa, R. Ferrari, M. De Paola, F. Rossi, A. Mariani, I. Caron, E. Sammali, M. Peviani, V. Dell'Oro, C. Colombo, M. Morbidelli, G. Forloni, G. Perale, D. Moscatelli and P. Veglianese, J. Controlled Release, 2014, 174, 15-26.

49 D. Yang, W. Chen and J. Hu, J. Phys. Chem. B, 2014, 118, 12311-12317.

50 D. Jung, S. Maiti, J. H. Lee, J. H. Lee and J. S. Kim, Chem. Commun., 2014, 50, 3044-3047.

51 M. H. Lee, J. H. Han, J.-H. Lee, H. G. Choi, C. Kang and J. S. Kim, J. Am. Chem. Soc., 2012, 134, 17314-17319.

52 N. V. Tsarevsky, S. A. Bencherif and K. Matyjaszewski, Macromolecules, 2007, 40, 4439-4445.

53 S. Luo, E. Zhang, Y. Su, T. Cheng and C. Shi, Biomaterials, 2011, 32, 7127-7138.

54 L. Shang, K. Nienhaus and G. U. Nienhaus, J. Nanobiotechnol., 2014, 12, 5.

55 C. Colombo, L. Galletti, M. Lepri, I. Caron, L. Magagnin, P. Veglianese, F. Rossi and D. Moscatelli, Eur. Polym. J., 2015, 68, 216-225.

56 R. Dringen, Prog. Neurobiol., 2000, 62, 649-671.

57 K. Aquilano, S. Baldelli and M. R. Ciriolo, Front. Pharmacol., 2014, 5, 196.

58 C. Hwang, A. J. Sinskey and H. F. Lodish, Science, 1992, 257, 1496-1502.

59 G. Leriche, L. Chisholm and A. Wagner, Bioorg. Med. Chem., 2012, 20, 571-582. 